\title{
Microsatellite fingerprinting of barley scald pathogen, Rhynchosporium secalis, from the Hokuriku and Tohoku districts in Japan and genetic resources of barley breeding for resistance to its pathogen population
}

\author{
Kazunari Takeuchi and Toshinori Fukuyama* \\ Graduate School of Science and Technology, Niigata University, Ikarashi 2, Nishiku, Niigata 950-2181, Japan
}

\begin{abstract}
Variation in pathogenicity and microsatellite marker haplotype was investigated in 107 isolates of barley scald pathogen, Rhynchosporium secalis, collected from the Hokuriku and Tohoku districts in Japan during 2004 and 2005. By inoculation using 18 differential cultivars, 58 pathotypes were identified with complex variation in pathogenicity with no predominant pathotype. Among the 18 differential cultivars, Osiris exhibited highly stable resistance to all the isolates. As some differential cultivars with the same resistance gene(s) showed the different reaction pattern to the pathotypes, these differential cultivars may have unknown resistance gene(s) specific to Japanese isolates. DNA polymorphism was detected by 13 microsatellite markers to obtain 63 haplotypes that were classified into 6 clusters (I-VI). Two clusters (I and III) covered a broad region, and the remaining 4 covered a relatively limited region. Cluster VI was distributed only in Yamagata, and the isolates in this cluster showed higher pathogenicity than those in the other 5 clusters. Therefore, for resistance against the pathotypes in cluster VI, some differential cultivars including Osiris were recommended as genetic resources for scald resistance in barley breeding. Finally, the possibility of monitoring using microsatellite markers was discussed.
\end{abstract}

Key Words: barley scald, Rhynchosporium secalis, pathotype, resistance resource, microsatellite haplotype, fingerprinting.

\section{Introduction}

Scald caused by the haploid imperfect fungus Rhynchosporium secalis (OUDEMANS) J. J. Davis occurs worldwide in barley cultivation. In Japan, the disease is especially found in the districts of Hokuriku and Tohoku, which are on the coast of the Japan Sea. These districts are covered with heavy snow in winter making a prime condition for a scald epidemic causing reportedly heavy losses of yield and grain quality (Ozoe 1956). However, development of a more desirable breeding of highly resistant cultivars based on the gene-for-gene theory is difficult due to the complexity of the pathogenicity of $R$. secalis, as was found in the case of the resistant cultivar Atlas 46, which was susceptible 9 years after being commercially available in California, USA, in 1947 (Houston and Ashworth 1957).

Unlike the wheat stem rust Puccinia graminis Persoon $\mathrm{f}$. sp. tritici that is spread globally by airborne infection, conidia of $R$. secalis are transported over short distances by water splash dispersal (Ozoe 1956), suggesting that endemic pathotypes distribute locally. In fact, much evidence suggests that there is a wide spectrum of pathogenicity in most

Communicated by H. Tsujimoto

Received November 4, 2008. Accepted January 20, 2009.

*Corresponding author (e-mail: fukuyama@agr.niigata-u.ac.jp)
$R$. secalis populations in various countries (Ali et al. 1976, Ceoloni 1980, Goodwin et al. 1992, Jackson and Webster 1976, Jørgensen and Smedegaard-Petersen 1995, Robbertse et al. 2000, Salamati and Tronsmo 1997, Tekauz 1991), and little evidence of limited pathogenicity (Brown 1985, Cromey 1987, Robinson et al. 1996, Williams and Owen 1973).

In one Japanese study, 37 isolates of $R$. secalis collected from various locations were classified into 10 races (Kajiwara and Iwata 1963). Furthermore, Fukuyama et al. (1998) identified 36 different pathotypes from 38 isolates collected from the Hokuriku district in 1992, 1993 and 1995 based on reactions of 14 differential cultivars used internationally, and they suggested that the isolates collected from the southern part of the district are more aggressive than those from the northern part.

Outside Japan, genetic diversity of the $R$. secalis population has recently been demonstrated using DNA markers, such as restriction fragment length polymorphism (RFLP) (McDonald et al. 1999, Salamati et al. 2000), random amplified polymorphic DNA (RAPD) and amplified fragment length polymorphism (AFLP) (Von Korff et al. 2004, KirosMeles et al. 2005). These studies did not report on the interrelationship between pathogenic and genetic variation. On the other hand, Newton et al. (2001) has reported no correlation between race, virulence and the RAPD profile, while 
Bouajila et al. (2007) found no correlation between pathotype and AFLP haplotype among isolates collected in Tunisia. However, DNA marker analysis may be a useful tool not only for understanding the interrelationships between pathogenic and genetic variation in $R$. secalis, but also for fingerprinting of the pathogen and monitoring of its pathogen population structure. In this study, we investigated the variations in pathotype and haplotype of the microsatellite loci in $R$. secalis collected from the Hokuriku and Tohoku districts in Japan and then examined their relationship. Here, we propose fingerprinting and monitoring of the $R$. secalis as methods for analysis of the pathogen population structure, and genetic resources of host corresponding to the pathogen population.

\section{Materials and Methods}

\section{Field sampling and isolation of the pathogen}

Leaves of barley, Hordeum vulgare L. cv. Minorimugi with scald symptoms were collected within the Hokuriku and Tohoku districts from 19 and 18 different locations in 2004 and 2005, respectively (Fig. 1). In each location, 2 or 3 leaves were collected from different plants. To isolate $R$. secalis, leaves with scald lesions were cut, surface sterilized $(20 \mathrm{sec}$ in $80 \%$ ethanol, followed by $2 \mathrm{~min}$ in $1 \% \mathrm{NaOCl})$ and rinsed twice in sterile water. After removing excess water with filter paper, leaf sections were placed on plates of potato-agar medium supplemented with $2 \%$ sucrose and

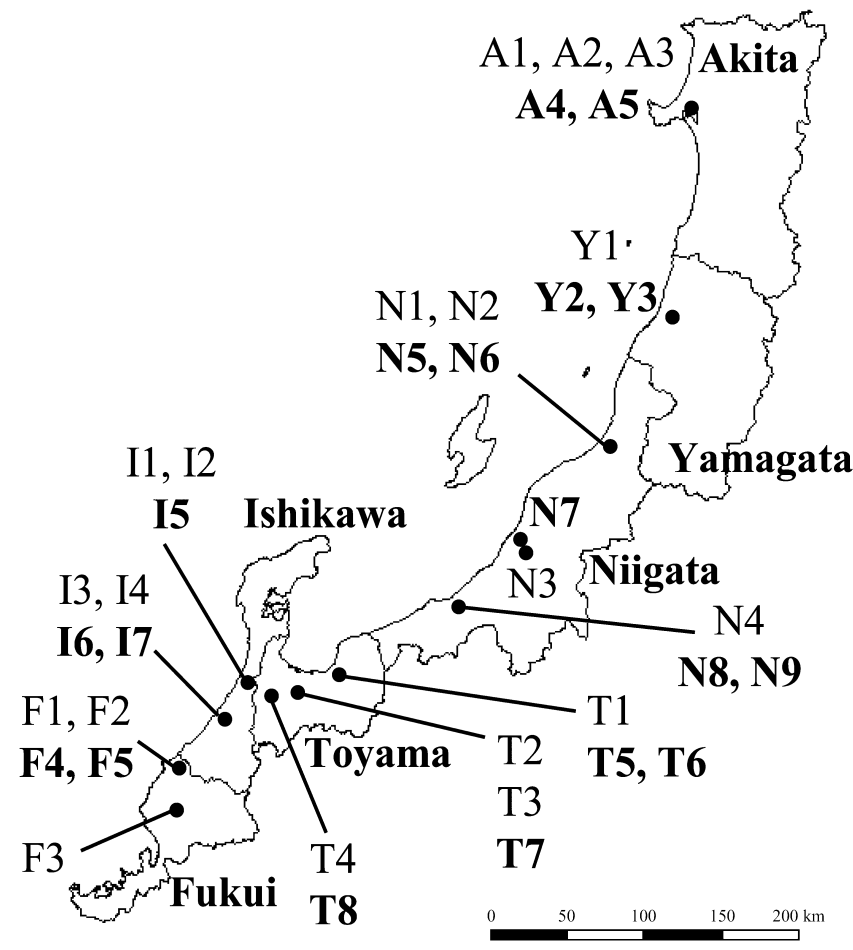

Fig. 1. Collection sites of $R$. secalis from the Hokuriku and Tohoku districts. Barley field samples in 2004 and 2005 are alphanumerically abbreviated in normal and bold font, respectively. incubated at $20^{\circ} \mathrm{C}$ under darkness. After 2-week incubation, dilutions of spore suspensions were prepared to obtain a single spore suspension that was cultured on a fresh plate of medium. The isolated mycelial colonies were stored at $4{ }^{\circ} \mathrm{C}$ until inoculation. The nomenclature of isolates are designated alphanumerically by the first letter of the collecting location and the field number, respectively (e.g., A1 was collected from field No. 1 of Akita Prefecture), followed by an additional number indicating the plant source.

\section{Differential cultivars and inoculation}

To detect the spectrum of pathogenicity, each isolate was inoculated to 5 separate plants each for a total of 18 differential cultivars, 14 from Fukuyama et al. (1998) and 4 new differential cultivars, CI 4364, CI 4368, Jet and Steudelli (Table 1). The 18 cultivars and Minorimugi as a susceptible control were grown in plastic seedling cases $(26 \times 18 \times 8 \mathrm{~cm})$ containing a soil mix (pot soil No. 1, Honen-agri, Japan) with $4.0 \mathrm{~g}$ fertilizer $\left(\mathrm{N}: \mathrm{P}_{2} \mathrm{O}_{5}: \mathrm{K}_{2} \mathrm{O}=14: 10: 13 \%\right)$. When seedlings grew to the 1.5-leaf stage, the spore suspension (adjusted concentration, $5 \times 10^{5}$ spores $/ \mathrm{ml}$ ) was sprayed at the rate of $50 \mathrm{ml}$ per seedling case. Each case was then covered by a plastic bag and kept at $20^{\circ} \mathrm{C}$ to maintain $100 \%$ relative humidity and to avoid contamination between isolates. After $48 \mathrm{~h}$, plants were transferred to a greenhouse with a temperature range of $15-25^{\circ} \mathrm{C}$. Inoculation was repeated two periods, December 2004 to February 2005 for the isolates collected in 2004 and November 2005 to January 2006 for those collected in 2005 .

Table 1. Differential barley cultivars used in this study and their resistance genotype to scald

\begin{tabular}{|c|c|}
\hline $\begin{array}{l}\text { Differential cultivar } \\
\text { (Abbreviation) }\end{array}$ & Scald resistance gene ${ }^{a}$ \\
\hline Abyssinian (Aby) & $\operatorname{Rrs} 9$ \\
\hline Atlas (Atl) & Rrs 2 \\
\hline Atlas 46 (A46) & $\operatorname{Rrs} 2, \operatorname{Rrs} 3$ \\
\hline Bey & $\operatorname{Rrs} 3$ \\
\hline Brier (Bri) & $\operatorname{Rrs} 1, \operatorname{rrs} 6$ \\
\hline CI 3515 (C35) & $\operatorname{Rrs} 4, \operatorname{Rrs} 10, \operatorname{Rrs}$ at $\operatorname{Rrs} 1-\operatorname{Rrs} 3-\operatorname{Rrs} 4$ complex \\
\hline CI 4364 (C64) & $\operatorname{rrs} 11$ \\
\hline CI 4368 (C68) & $\operatorname{rrs} 11$ \\
\hline CI 8256 (C82) & $\operatorname{Rrs} 4, \operatorname{Rrs} 10, \operatorname{Rrs}$ at $\operatorname{Rrs} 1-\operatorname{Rrs} 3-\operatorname{Rrs} 4$ complex \\
\hline Jet & $\operatorname{rrs} 6, \operatorname{rrs} 7$ \\
\hline Kitchin (Kit) & $\operatorname{Rrs} 9$ \\
\hline La Mesita (LaM) & $\operatorname{Rrs} 4, \operatorname{Rrs} 10, \operatorname{Rrs}$ at $\operatorname{Rrs} 1-\operatorname{Rrs} 3-\operatorname{Rrs} 4$ complex \\
\hline Modoc (Mod) & $\operatorname{Rrs} 2, \operatorname{Rrs} 4, \operatorname{rrs} 6$ \\
\hline Nigrinudum (Nig) & $r r s 8$ \\
\hline Osiris (Osi) & $\operatorname{Rrs} 4, \operatorname{rrs} 6, \operatorname{Rrs} 10$ \\
\hline Rivale (Riv) & $\operatorname{Rrs} 3$ \\
\hline Steudelli (Ste) & $\operatorname{rrs} 6, \operatorname{rrs} 7$ \\
\hline Turk (Tur) & $\operatorname{Rrs} 1, \operatorname{Rrs} 3, \operatorname{Rrs} 5, r r s 6$ \\
\hline
\end{tabular}

${ }^{a}$ Table was adapted from that of H. O. Pinnschmidt and Jakob Willas and available on the International Barley Scald Working Group website (http://www.crpmb.org/scald/). 
Assessment of disease

Symptoms on the second leaf of the differential cultivars were assessed 21 days after inoculation according to the following scale: $\mathrm{R}$, no visible symptoms or a few lesions of $<5$-mm diameter with necrosis; $\mathrm{S}$, large blue-gray lesions of $\geq 5$-mm diameter without necrosis or coalescing lesions. When at least 1 out of 5 plants showed S characteristics, the differential was deemed susceptible.

\section{DNA extraction}

For DNA extraction, fungi were grown in $50 \mathrm{ml}$ potato liquid medium supplemented with $2 \%$ sucrose in $100-\mathrm{ml}$ Erlenmeyer flasks at $20^{\circ} \mathrm{C}$ for $10-12$ days on an orbital shaker. The resulting mycelial colonies were then ground using a mortar and pestle under liquid nitrogen. Total cellular DNA was isolated from the powdered mycelial colonies according to Adachi et al. (1993) and then stored at $4^{\circ} \mathrm{C}$.

\section{PCR amplification and microsatellite analysis}

For fingerprinting of $107 \mathrm{R}$. secalis isolates, 14 primer pairs of microsatellite markers developed by Linde et al. (2005) were used for PCR analysis on a PCR Thermal Cycler Dice Gradient (Takara Bio, Inc., Shiga, Japan). The 10- $\mu$ l PCR reaction mixtures contained $10-50 \mathrm{ng}$ total DNA, $1.0 \mu \mathrm{l} 10 \times \mathrm{EX}$ Taq buffer, $0.4 \mathrm{mM}$ dNTP mixture, $0.25 \mu \mathrm{M}$ each of the forward and reverse primers and $0.25 \mathrm{U}$ Taq polymerase (Ex TaqTM, Takara Bio). PCR conditions were $96^{\circ} \mathrm{C}$ for $2.5 \mathrm{~min}, 36$ cycles of denaturation for $30 \mathrm{sec}$ at $96^{\circ} \mathrm{C}$, annealing for $30 \mathrm{sec}$ at $56^{\circ} \mathrm{C}$ and elongation for $1 \mathrm{~min}$ at $72^{\circ} \mathrm{C}$. The extension time of the final cycle was $10 \mathrm{~min}$ at $72^{\circ} \mathrm{C}$. The PCR products were electrophoresed in $10 \%$ polyacrylamide gels at $250 \mathrm{~V}$ for about $3 \mathrm{~h}$ and visualized using silver staining. Polymorphism was visually distinguished by band patterns, which were numerically labeled in descending order of size.

To compare the genetic variation between isolates, cluster analysis was performed using POPGENE version 1.32 software (Yeh and Boyle 1997) and dendrograms were constructed based on unbiased genetic distances (Nei 1978) with the unweighted pair-group method with arithmetic mean (UPGMA).

\section{Results}

Pathogenicity of $\mathrm{R}$. secalis isolates on 18 differential cultivars

All plants of the susceptible control cv. Minorimugi resulted in typical S reactions, indicating optimal epidemic infection conditions in the inoculation test. Repeating the method for pathotype differentiation in November 2005 by retesting 3 random isolates used in the previous year resulted in the same reaction spectra to the 18 cultivars.

A total of $107 R$. secalis isolates were classified into 58 different pathotypes, designated pathotype 1 to 58 , based on the reaction spectra of the seedlings to 18 cultivars (Fig. 2); Fig. 2 arranges the cultivars according to their resistance genotype. All pathotypes consisted of 1-4 isolates, except for pathotypes 39 and 47, which consisted of 7 and 8 isolates, respectively. No clearly predominant pathotype was observed in the Hokuriku and Tohoku districts. Among the 58 pathotypes, the number of susceptible cultivars out of the 18 differentials ranged from 0 to 14 . The isolate Y3.3 (pathotype 58) collected from Yamagata in 2005 was pathogenic to the most (14) differentials, followed by Y3.1 (pathotype 57) with 12 cultivars. The remaining 4 isolates (pathotypes 51-53 and 56) from Yamagata in 2005 also

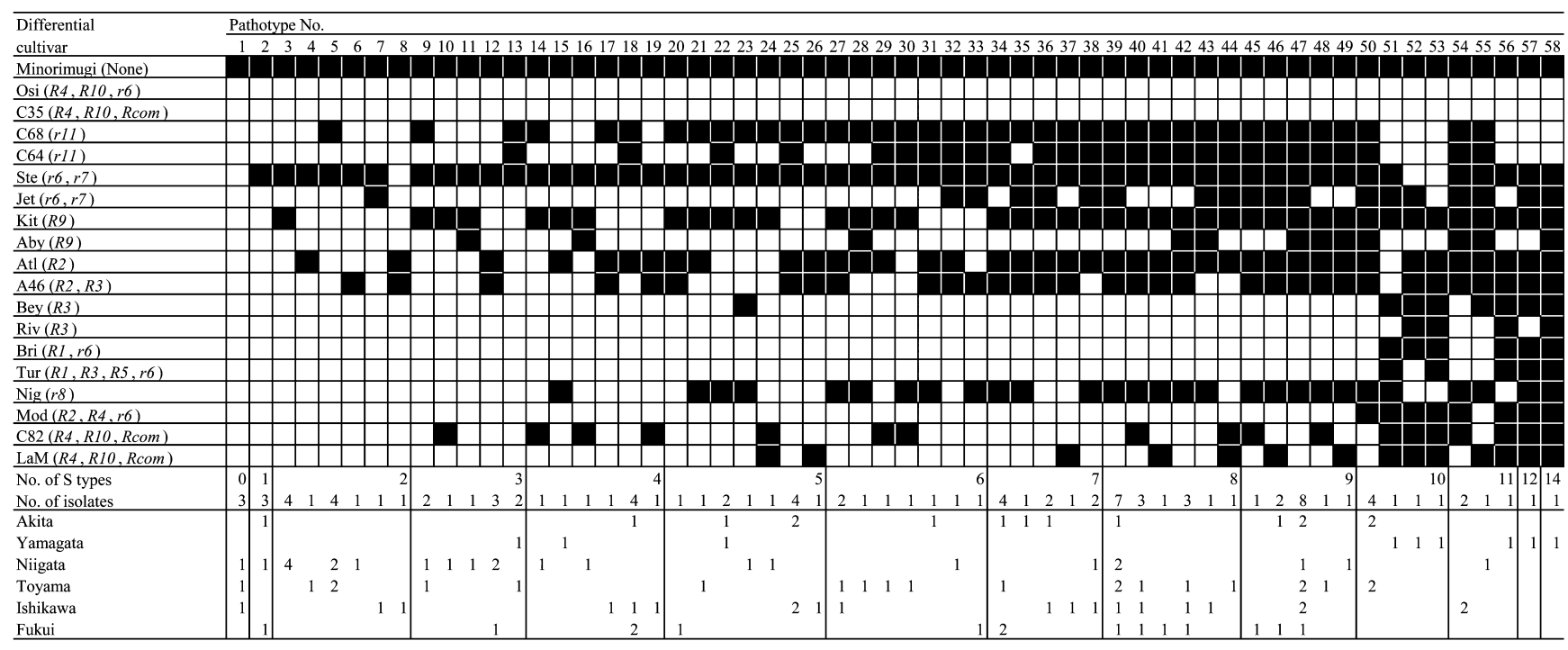

Fig. 2. Reaction pattern of 18 differential barley cultivars to 107 isolates of $R$. secalis and prefectural distribution of the pathotypes. The black and white squares indicate susceptibility and resistance, respectively. $R$ and $r$ in the parenthesis refer to the dominant (Rrs) and recessive ( $r r s$ ) resistance gene, respectively, followed by the number or com denoting the gene or Rrs 1-3-4 complex, respectively. The cv. Minorimugi was included as the susceptible control and was not included in the number of susceptible reaction types. 
showed a relatively wide pathogenicity ranging from 10 to 11 differentials, while all 3 isolates from Yamagata in 2004 showed narrower pathogenicity ranging from 3 to 5 . In contrast, the isolates of I1.2, T3.1 and N6.3 were pathogenic to none of the 18 differential cultivars, except for the control cv. Minorimugi.

Among the 18 differential cultivars, Osiris and CI 3515 were resistant to all isolates collected from the Hokuriku and Tohoku districts. Rivale, Turk and Brier were resistant to all isolates, except 4, 5, and 6 pathotypes from Yamagata, respectively. CI 4364 and CI 4368 were highly resistant to Yamagata isolates, but susceptible to a number of the remaining isolates. From the viewpoint of resistance genotype, it was shown that Steudelli and Jet had quite different reaction spectra to 58 pathotypes, nevertheless possessing the same resistance genes of $r r s 6$ and $r r s 7$; Steudelli was resistant to only 4 pathotypes, while Jet was resistant to 39 , with different spectra among 37 pathotypes. Similarly, Kitchin and Abyssinian, which possess a common resistance gene $\operatorname{Rrs} 9$, also had different spectra among 29 pathotypes, with resistance to 17 and 46 pathotypes, respectively. Moreover, a paradoxical reaction spectrum was observed in CI 4364 and CI 4368, which possess a common resistance gene rrs 11; CI 4364 was resistant to 19 pathotypes and CI 4368 was resistant to 31 , with different spectra among 12 pathotypes. These 2 differential cultivars were commonly resistant to pathotypes 51 to 53 and 56 to 58 with widest spectrum of pathogenicity collected from Yamagata. In the case of Atlas and Atlas 46 on the reaction to pathotypes 6 and 33, Atlas (Rrs2) was resistant to both pathotypes, while Atlas 46 (Rrs3 and Rrs2) was susceptible to both pathotypes.

\section{Microsatellite polymorphisms and cluster analysis}

All the microsatellite loci, except for Rhyncho_9, in the $R$. secalis populations collected from the Hokuriku and Tohoku districts were polymorphic. The number of alleles per polymorphic locus ranged from 4 to 9 . Cluster analysis of the 63 microsatellite haplotypes detected in the 13 loci showed isolate populations tentatively classified into clusters I-VI (Fig. 3). Most isolates collected from the same field were grouped in the same cluster; however, isolates from A3 were classified separately into clusters I and III, isolates from N6 and T5 into II and III, and isolates from I2, I6 and F5 into III and IV.

The distribution of these clusters by district showed that clusters I and III covered a broad region except for a part of Niigata; cluster II covered from the central region of Niigata to the eastern region of Toyama and Fukui; cluster IV covered Toyama, Ishikawa and Fukui; and clusters V and VI covered only the northern parts of Niigata and Yamagata, respectively (Fig. 4). Cluster VI was distributed the farthest from the other 5 clusters and included 6 isolates with the widest spectra of pathogenicity collected from Yamagata in 2005 .
Comparison of pathogenicity and microsatellite marker variation

The interrelationship between the variation in pathogenicity and haplotype of microsatellite markers was compared with isolates having the same haplotype by examining their reaction spectra to 18 differential cultivars. The ratio of the number of differential cultivars showing coincident reaction to isolates with the same haplotype relative to the 18 differential cultivars was used to calculate the degree of coincidence (Table 2). For instance, 4 isolates from A1.1, A4.1, A4.2 and A4.3 with the same allele in each of the 13 microsatellite loci expressed the same spectra of pathogenicity on 12 out of 18 differential cultivars; thus, the degree of coincidence is calculated as $0.67(12 / 18)$. Of the 63 microsatellite haplotypes, 27 were compared, as they consisted of 2 to 5 isolates with the same haplotype. The degree of coincidence ranged from 0.44 to 1.0 with the total mean of 0.78 . Complete coincidence (1.0) was found in clusters II and V, both of which consisted of only 2 isolates. These results indicate that fingerprinting with microsatellite markers may be possible to identify pathogenicity of about $80 \%$ of the isolates; the remaining $20 \%$ possessed the same haplotype but could be highly variable in pathogenicity.

A characteristic relationship was observed between pathogenicity and the allele at the microsatellite locus of the 6 isolates collected from Yamagata. The 6 isolates were clearly classified into a genetically different group (cluster VI) with high pathogenicity to Rivale, Turk and Brier not observed in the isolates of cluster I-V (Table 3). Moreover, after screening all 63 haplotypes, it was confirmed that only these 6 isolates contained a characteristic band ( $205 \mathrm{bp})$ of the microsatellite marker Rhyncho_12 corresponding to allele 4 (Fig. 5)

\section{Discussion}

In the present study, a remarkable pathogenic variation among the $R$. secalis population was confirmed in the Hokuriku and Tohoku districts. The 107 isolates of $R$. secalis were classified into 58 different pathotypes by an inoculation test using 18 differential cultivars (Fig. 2). Such complex variation in pathogenicity of $R$. secalis in these areas presents a difficult environment to breed resistance cultivars using major resistance gene(s) based on the gene-for-gene theory. We found that Osiris and CI 3515 may be effective breeding materials against scald due to their resistance to all 107 isolates. Fukuyama et al. (1998) reported that Brier and Turk, as well as Osiris, were resistant to all 38 isolates they collected from the Hokuriku district, while CI 3515 was susceptible to those from Niigata, Toyama and Nagano. In contrast, we revealed that Brier and Turk were susceptible only to the isolates from Yamagata. These contradicting findings may originate from the progress of diversity in pathogenicity over the 10- to 15-year period between studies. Notably, the resistance of Osiris was maintained over this period.

Osiris has the scald resistance genes, Rrs4, rrs6 and 


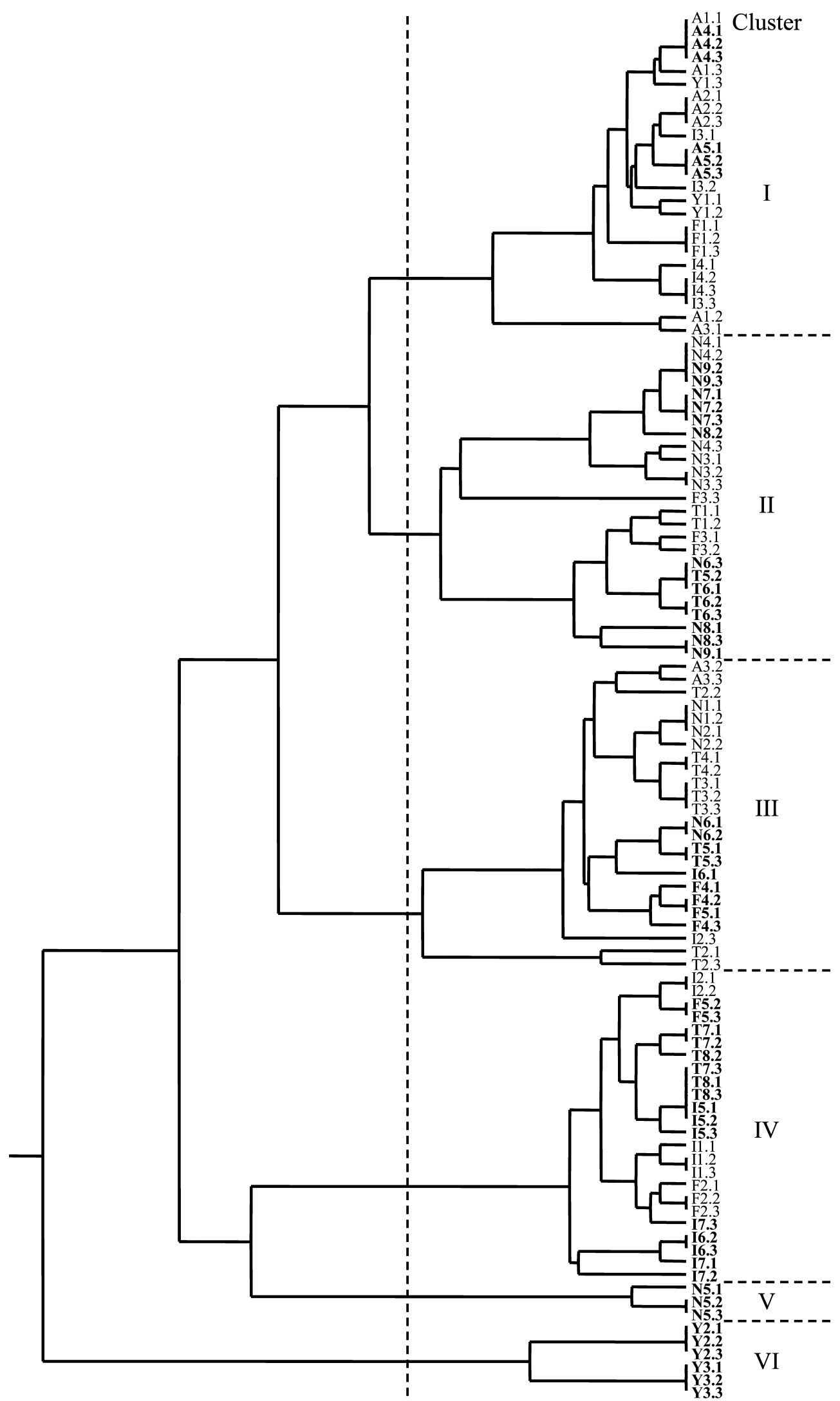

Fig. 3. Dendrogram showing Nei's (1978) unbiased genetic distance among 107 isolates based on the microsatellite analysis. Each isolate is designated alphanumerically by the collecting location of the sample (e.g., A1), followed by an additional number indicating the plant source. The isolates written in normal or bold font indicate the collection year of 2004 and 2005, respectively. Dashed lines tentatively divide the samples into clusters I-VI. 


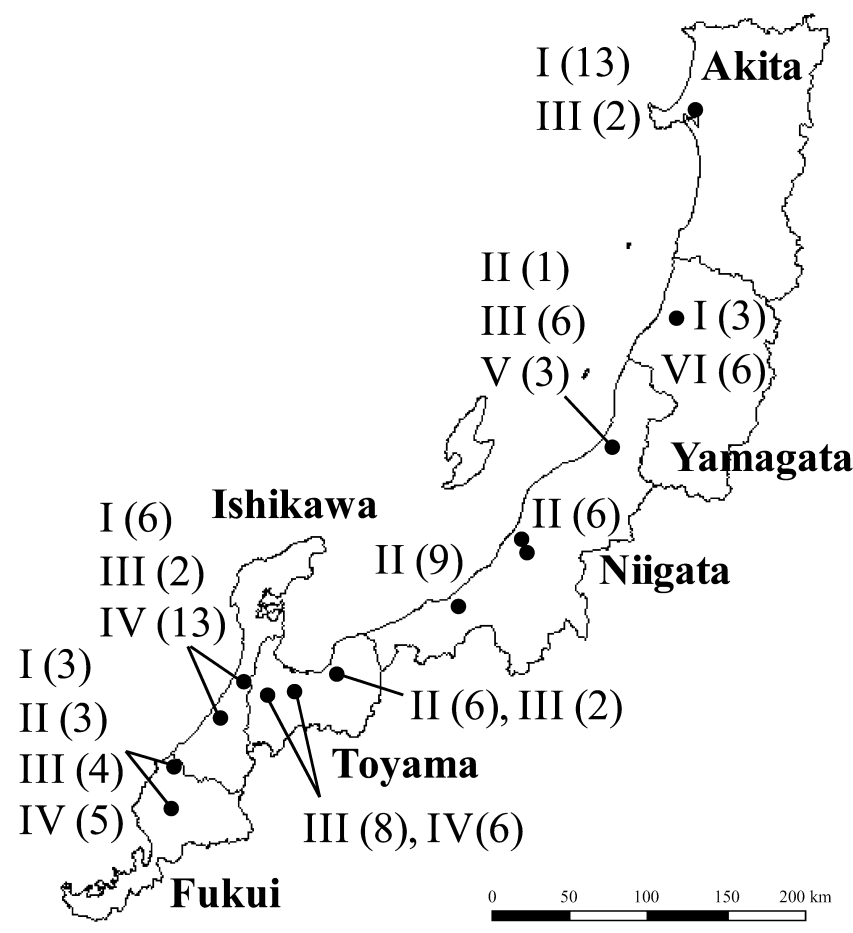

Fig. 4. Distribution of clusters in the Hokuriku and Tohoku districts. The number in parenthesis indicates the number of isolates in each cluster.

Rrs10 (Table 1), some of which are also included in CI 8256 and La Mesita (Rrs4, Rrs 10), Modoc (Rrs4, rrs6) and Brier, Jet and Steudelli (rrs6). Although Osiris was completely resistant, these other differential cultivars were susceptible to some isolates used in this study. These results indicate that Osiris may have resistance gene(s) other than Rrs 4, rrs6 and Rrs 10 that are resistant to the isolates from the Hokuriku and Tohoku districts.

A similar discrepancy in the resistance genotype and the reaction to isolates was also observed in Abyssinian and Kitchin (Rrs9), CI 4364 and CI 4368 (rrs 11), Bey and Rivale (Rrs3), and Steudelli and Jet (rrs6, rrs7). For instance, although they possess the same two resistance genes, Steudelli and Jet, which were identified by inoculation test using Canadian isolate (Baker and Larter 1963), showed different reactions to 37 out of 58 pathotypes, indicating that pathogenicity may be markedly different between isolates from Canada and Japan. We suggest that in addition to possessing rrs6 and rrs7, Jet may have other resistance gene(s) that are specifically resistant to isolates from Japan. Moreover, our preliminary studies suggest that Jet has longer latent periods (the number of days from inoculation to visible symptom) than those of Steudelli, indicating unique quantitative resistance factors in Jet (unpublished data).

In addition, we observed unexpected reactions of Atlas and Atlas 46 to pathotypes 6 and 33. Compared to Atlas, Atlas 46, which was developed by crossing Atlas and Turk, retains at least one more resistance gene (Rrs3) from Turk. However, while Atlas was resistant, Atlas 46 was susceptible to both pathotypes 6 and 33. These similar reactions of Atlas and Atlas 46 have been reported in the isolates from various countries including the UK (Williams and Owen 1973), Norway (Salamati and Tronsmo 1997), Denmark (Jørgensen and Smedegaard-Petersen 1995), Canada (Tekauz 1991), Japan (Fukuyama et al. 1998) and the USA

Table 2. Degree of coincidence between microsatellite haplotypes and the reaction to the 18 differential cultivars ${ }^{a}$

\begin{tabular}{|c|c|c|c|c|c|c|c|}
\hline & \multicolumn{6}{|c|}{ Cluster } & \multirow{2}{*}{ Mean } \\
\hline & I & II & III & IV & $\mathrm{V}$ & VI & \\
\hline No. of compared haplotypes & 5 & 6 & 6 & 7 & 1 & 2 & \\
\hline Range & $0.67-0.94$ & $0.44-1.00$ & $0.56-0.94$ & $0.61-0.94$ & 1.00 & $0.78-0.83$ & \\
\hline Mean & 0.78 & 0.71 & 0.78 & 0.79 & 1.00 & 0.81 & 0.78 \\
\hline
\end{tabular}

${ }^{a}$ Calculation of the degree of coincidence is described in the Results section.

Table 3. Pathogenicity of the isolates in each cluster to 7 differential cultivars and microsatellite marker identifying cluster VI

\begin{tabular}{|c|c|c|c|c|c|c|c|c|}
\hline \multirow{2}{*}{ Cluster No. ${ }^{a}$} & \multicolumn{7}{|c|}{ Differentials $^{b}$} & \multirow{2}{*}{$\begin{array}{l}\text { Microsatellite alleles }^{c} \\
\text { Rhyncho_12 (size (bp)) }\end{array}$} \\
\hline & Osi & $\mathrm{C} 35$ & Bri & Riv & Tur & C68 & C64 & \\
\hline VI (6) & $\mathrm{R}$ & $\mathrm{R}$ & $\mathrm{S}$ & $\mathrm{S}$ & $\mathrm{S}$ & $\mathrm{R}$ & $\mathrm{R}$ & $4(205)$ \\
\hline \multicolumn{9}{|l|}{ Others } \\
\hline I (25) & $\mathrm{R}$ & $\mathrm{R}$ & $\mathrm{R}$ & $\mathrm{R}$ & $\mathrm{R}$ & $\mathrm{R} / \mathrm{S}$ & $\mathrm{R} / \mathrm{S}$ & $2(225)$ \\
\hline II $(25)$ & $\mathrm{R}$ & $\mathrm{R}$ & $\mathrm{R}$ & $\mathrm{R}$ & $\mathrm{R}$ & $\mathrm{R} / \mathrm{S}$ & $\mathrm{R} / \mathrm{S}$ & $1(230), 5(203)$ \\
\hline III (24) & $\mathrm{R}$ & $\mathrm{R}$ & $\mathrm{R}$ & $\mathrm{R}$ & $\mathrm{R}$ & $\mathrm{R} / \mathrm{S}$ & $\mathrm{R} / \mathrm{S}$ & $2(225)$ \\
\hline IV (24) & $\mathrm{R}$ & $\mathrm{R}$ & $\mathrm{R}$ & $\mathrm{R}$ & $\mathrm{R}$ & $\mathrm{R} / \mathrm{S}$ & $\mathrm{R} / \mathrm{S}$ & $3(215)$ \\
\hline $\mathrm{V} \quad$ (3) & $\mathrm{R}$ & $\mathrm{R}$ & $\mathrm{R}$ & $\mathrm{R}$ & $\mathrm{R}$ & $\mathrm{R}$ & $\mathrm{R}$ & $2(225)$ \\
\hline
\end{tabular}

${ }^{a}$ Numbers in parenthesis indicates the number of the isolates.

${ }^{b} \mathrm{R}$ and $\mathrm{S}$ indicate resistance and susceptibility, respectively; R/S indicates both resistance and susceptibility within the cluster.

${ }^{c}$ Cluster II contains 2 alleles; allele 5 is amplified only in isolate F3.3. The fragment sizes were approximated by the molecular weight markers (see Fig. 5). 


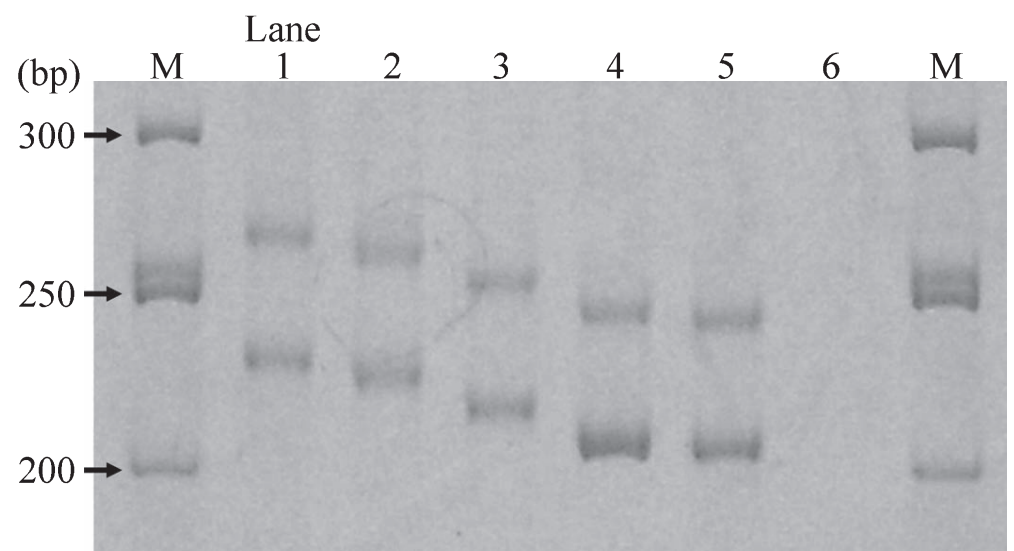

Fig. 5. Microsatellite band patterns of $R$. secalis isolates using primer Rhyncho_12. Lane M, molecular weight markers with the sizes indicated on the left side of the gel. Lanes 1-5, alleles 1-5 (Table 3), respectively; Lane 6, negative control.

(Jackson and Webster 1976, Goodwin et al. 1992), suggesting that Atlas possesses unknown resistance gene(s) that are resistant to specific isolates such as pathotypes 6 and 33, which have never been used in the resistance gene evaluation for Atlas 46. Recently, Nakamura-Aoki et al. (2008) reported that Brier $(R r s 1, r r s \sigma)$ possesses one dominant and three recessive genes resistant to the isolate in the Hokuriku district and clearly showed that Brier has at least two different recessive genes other than rrs6. Thus, selection of an appropriate isolate or pathotype is important for effective screening of resistance gene(s) in the breeding program.

Using fingerprinting with microsatellite markers, we detected 63 haplotypes in 13 different microsatellite loci and classified them into 6 clusters (I-VI). Most isolates from a single field tended to belong to the same cluster (Fig. 2). This genetic similarity within a single field may be due to the locally restricted conidia reproduction of $R$. secalis population during the imperfect stage. Von Korff et al. (2004) reported that genetic diversity within populations collected from the same region accounted for $20 \%$ of the total genetic diversity with 65 isolates, suggesting that high genetic similarity within the same location originates from a local founder population, possibly through rain-splash dispersed conidia. Moreover, Williams et al. (2003) reported high genetic similarity between isolates from the same hotspot, which is supported by our findings.

Clusters I and III were found in broad regions in the Hokuriku and Tohoku districts. However, with the current Japanese barley production system, the pathogen of these clusters is less likely to migrate over the prefectures through infected seeds or straw. This wide distribution of clusters I and III may be attributed to the genetically similar population dispersed by large epidemics of scald all over Japan in the latter half of the 1940s (Kajiwara and Iwata 1963) or the outbreak across the Hokuriku district in the 1980s (Yoshino and Takenaka 1986). Clusters V and VI were characteristic in geographical distribution and pathogenicity despite the small sample size; $\mathrm{V}$ was restricted in the northern part of Niigata with a narrow spectrum of pathogenicity and VI covered only Yamagata with a wide spectrum. These restricted distributions of clusters V and VI may be due to the endemic characteristics of $R$. secalis, as well as their relatively recent appearance in Niigata and Yamagata, respectively. As for the range of pathogenicity, the differences between cluster $\mathrm{V}$ and $\mathrm{VI}$ is unclear.

From the calculations of the degree of coincidence between pathotype and microsatellite haplotype (Table 2), we determined the pathogenicity of about $80 \%$ of the isolates by fingerprinting with 13 microsatellite markers, but not that of the remaining $20 \%$ or more, even though they possessed the same haplotype. While Newton et al. (2001) indicates no clear relationship between genetic and pathogenic variation, Bouajila et al. (2007) more recently suggests that random molecular variation from mutations may have accumulated within the individual pathotypes, resulting in little correlation. Taken together with our findings, $R$. secalis appears to be a highly intractable pathogen requiring special consideration during resistance breeding.

In contrast to the 5 differential cultivars indicated in Table 3, Osiris, CI 3515, Brier, Rivale and Turk, that show effective resistance against $R$. secalis in the regions covering clusters I-V, only Osiris, CI 3515, CI 4364 and CI 4368 are recommended as resistance resources in the region covering the isolates of cluster VI. CI 4364 and CI 4368 are particularly interesting due to their susceptibility to many isolates of clusters I-V, but resistant to those in cluster VI. In comparison, Jackson and Webster (1976) reported that although Atlas was susceptible to their isolate groups I and II with a narrow spectrum of pathogenicity, it exhibited the highest degree of resistance to the isolates in their group III with a wide spectrum, indicating that factors other than those previously identified were being expressed in the reaction elicited by group III isolates. Therefore, factors included in CI 4364 and CI 4368 should be analyzed for their involvement in resistance breeding against isolates in cluster VI.

To develop breeding programs for scald resistance, careful consideration of occurrence, frequency and distribution is required for $R$. secalis isolates included in cluster VI due 
to their wide spectrum of pathogenicity. In the present study, we demonstrate the effectiveness of the fingerprinting method using microsatellite markers of $R$. secalis, and particular use of Rhyncho_ 12 for monitoring of isolates in cluster VI. Since the sample size was only 6 isolates from Yamagata in this study, we analyzed an additional 13 isolates collected in 2007. We have confirmed that these 13 isolates are pathogenic to Rivale, Turk and Brier and amplified the characteristic band of Rhyncho_12 (unpublished data). Taken together, cluster VI can be more easily and quickly monitored using Rhyncho 12, compared with the customary method that requires an isolation of single spores and an inoculation test to the differential cultivars. Additional markers would also be desirable to monitor the pathogen population with more accuracy.

This study has verified a notable pathogenic variation of R. secalis from the Hokuriku and Tohoku districts in Japan and revealed that some of the differential cultivars have unknown resistance gene(s) unique to isolates from these areas. Osiris is strongly recommended as a resistance resource in these districts due to its wide and stable pathogenic effectiveness against $R$. secalis. Further genetic analysis of Osiris using isolates included in cluster VI should be carried out by crossing it with Minorimugi, which is completely susceptible to the isolates from Hokuriku and Tohoku districts. Considering the variation in pathogenicity, many resistance resources that are highly diverse are desirable. We propose the use of additional differential cultivars such as CI 3515 , Brier, Rivale and Turk in the regions of clusters $\mathrm{I}-\mathrm{V}$ and CI 3515, CI 4364 and CI 4368 in the regions of cluster VI. Our fingerprinting method established in this study may be more convenient for monitoring of the pathogen population structure and for selection of resistance resources.

\section{Acknowledgments}

We sincerely thank Drs Kenji Kato and Kazuhiro Toyoda, Okayama University, for DNA analysis and extraction.

\section{Literature Cited}

Adachi, Y., H.Watanabe, K. Tanabe, N.Doke, S.Nishimura and T. Tsuge (1993) Nuclear ribosomal DNA as a probe genetic variability in the Japanese pear pathotype of Alternaria alternata. Appl. Environ. Microbiol. 59: 3197-3205.

Ali,S.M., A.H.Mayfield and B.G.Clare (1976) Pathogenicity of 203 isolates of Rhynchosporium secalis on 21 barley cultivars. Physiological Plant Pathology 9: 135-143.

Baker,R.J. and E.N.Larter (1963) The inheritance of scald resistance in barley. Can. J. Genet. Cytol. 5: 445-449.

Bouajila,A., M.M.Abang, S.Haouas, S.Udupa, S.Rezgui, M.Baum and A. Yahyaoui (2007) Genetic diversity of Rhynchosporium secalis in Tunisia as revealed by pathotype, AFLP, and microsatellite analyses. Mycopathologia 163: 281-294.

Brown, J.S. (1985) Pathogenic variation among isolates of Rhynchosporium secalis from cultivated barley growing in Victoria, Australia. Euphytica 34: 129-133.
Ceoloni,C. (1980) Race differentiation and search for sources of resistance to Rhynchosporium secalis in barley in Italy. Euphytica 29: 547-553.

Cromey,M.G. (1987) Pathogenic variation in Rhynchosporium secalis on barley in New Zealand. NZ. J. Agric. Res. 30: 95-99.

Fukuyama,T., S. Yamaji and H.Nakamura (1998) Differentiation of virulence in Rhynchosporium secalis in the Hokuriku district and sources of resistance to the pathogen. Breed. Sci. 48: 23-28.

Goodwin,S.B., R.W.Allard, S.A.Hardy and R.K.Webster (1992) Hierarchical structure of pathogenic variation among Rhynchosporium secalis populations in Idaho and Oregon. Can. J. Bot. 70: 810-817.

Houston,B.R. and L.J.AshworthJr. (1957) Newly determined races of the barley scald fungus in California. Phytopathology 47: 525.

Jackson, J.F. and R.K.Webster (1976) Race differentiation, distribution, and frequency of Rhynchosporium secalis in California. Phytopathology 66: 719-725.

Jørgensen,H.J.L. and V.Smedegaard-Petersen (1995) Pathogenic variation of Rhynchosporium secalis in Denmark and sources of resistance in barley. Plant Dis. 79: 297-301.

Kajiwara,T. and Y.Iwata (1963) Studies on the strains of barley scald fungus, Rhynchosporium secalis (Oud.) Davis. Bull. Nat. Inst. Agr. Sci., Series C, No. 15: 1-73.

Kiros-Meles, A., S.Udupa, M.M.Abang, H.Abu-Blan, M.Baum, S. Ceccarelli and A.H.Yahyaoui (2005) Amplified fragment length polymorphism among Rhynchosporium secalis isolates collected from a single barley field in Syria. Annals of Applied Biology 146: 389-394.

Linde,C.C., M.Zala and B.A.McDonald (2005) Isolation and characterization of microsatellite loci from the barley scald pathogen, Rhynchosporium secalis. Molecular Ecology Notes 5: 546-548.

McDonald,B.A., J.Zhan and J.J.Burdon (1999) Genetic structure of Rhynchosporium secalis in Australia. Phytopathology 89: 639645 .

Nakamura-Aoki,E., O. Yamaguchi, S.Ito, J.Moriwaki and T.Baba (2008) Genetic analysis of resistance to barley scald (Rhynchosporium secalis) in a field of the resistant cultivar Brier and its application to breeding. Breed. Res. 10: 101-110.

Nei,M. (1978) Estimation of average heterozygosity and genetic distance from a small number of individuals. Genetics 89: 583-590.

Newton, A.C., J.Searle, D.C.Guy, C.A.Hackett and D.E.L.Cooke (2001) Variability in pathotype, aggressiveness, RAPD profile, and rDNA ITS1 sequences of UK isolates of Rhynchosporium secalis. J. Plant Dis. Prot. 108: 446-458.

Ozoe,S. 1956. Studies on the Rhynchosporium scald of barley and its control. Bulletin of the Shimane Prefecture Agricultural Institute 1: $1-122$.

Robbertse, B., C.L.Lennox, A.B. van Jaarsveld, P.W.Crous and M. vanderRijst (2000) Pathogenicity of the Rhynchosporium secalis population in the Western Cape province of South Africa. Euphytica 115: 75-82.

Robinson,J., H.Lindqvist and M.Jalli (1996) Genes for resistance in barley to Finnish isolates of Rhynchosporium secalis. Euphytica 92: 295-300.

Salamati,S. and A.M.Tronsmo (1997) Pathogenicity of Rhynchosporium secalis isolates from Norway on 30 cultivars of barley. Plant Pathol. 46: 416-424.

Salamati,S., J.Zhan, J.J.Burdon and B.A.McDonald (2000) The genetic structure of field populations of Rhynchosporium secalis from three continents suggests moderate gene flow and regular recombination. Phytopathology 90: 901-908.

Tekauz,A. (1991) Pathogenic variation in Rhynchosporium secalis on 
barley in Canada. Canadian Journal of Plant Pathology 13: 298304.

Von Korff,M., S.M.Udupa, A.Yahyaoui and M.Baum (2004) Genetic variation among Rhynchosporium secalis populations of west Asia and north Africa as revealed by RAPD and AFLP analysis. J. Phytopathol. 152: 106-113.

Williams,R.J. and H.Owen (1973) Physiologic races of Rhynchosporium secalis on barley in Britain. Trans. Br. mycol. Soc. 60: 223-234.

Williams, K., S.Donnellan, C.Smyl, L.Scott and H.Wallwork (2003)
Molecular variation in Rhynchosporium secalis isolates obtained from hotspots. Australasian Plant Pathology 32: 257-262.

Yeh,F.C. and T.J.B.Boyle (1997) Population genetic analysis of codominant and dominant markers and quantitative traits. Belgian Journal of Botany 129: 157.

Yoshino,R. and S. Takenaka (1986) Control of major diseases of barley occurred in the Hokuriku area. Res. Rep. Agric. Dev. Hokuriku Area 16: 39-42. 